\title{
Late Manifestation of Struma Peritonei and Widespread Functioning Lesions in the Setting of Struma Ovarii Simulating Highly Differentiated Follicular Carcinoma
}

\author{
Rohit Ranade ${ }^{1}$, Swati Rachh ${ }^{2}$, and Sandip Basu ${ }^{1}$ \\ ${ }^{1}$ Radiation Medicine Centre, Bhabha Atomic Research Centre, Tata Memorial Centre Annexe, Parel, Mumbai, India; and \\ ${ }^{2}$ Department of Nuclear Medicine, Gujarat Cancer and Research Institute, Ahmedabad, India
}

\begin{abstract}
Malignant transformation of struma ovarii is a rare event observed in about $5 \%$ of cases. We present here an unusual case that closely simulated highly differentiated follicular carcinoma, an entity with a relatively similar appearance to malignant struma ovarii. In our case, peritoneal and systemic dissemination occurred 18 y after excision of struma ovarii, which had been reported as histopathologically benign. There were 3 noteworthy features in the case: the highly functioning nature of the lesions (evidenced by a low level of thyroid-stimulating hormone even without thyroxine suppression); the low to minimal ${ }^{18} \mathrm{~F}$ FDG avidity of the foci, which reiterates the well-differentiated nature of these lesions, as expected in highly differentiated follicular carcinoma; and prominent involvement of rare sites such as spleen and liver, in addition to usual sites such as lungs, peritoneum, and bilateral adnexae.
\end{abstract}

Key Words: peritoneal strumosis; struma ovarii; radioiodine scan; FDG PET/CT

J Nucl Med Technol 2015; 43:231-233

DOI: 10.2967/jnmt.114.149294

S

ruma ovarii is a rare monodermal variant of ovarian teratoma accounting for $2 \%$ of all mature teratomas. To be classified as struma ovarii, the teratoma must comprise predominantly mature thyroid tissue $(>50 \%)(1,2)$. The condition is benign, but malignant transformation can occur in around $5 \%$ of cases (3). It usually presents as a pelvic mass and in about $5 \%$ of cases may present as pseudo-Meigs' syndrome (4). Benign thyroid tissue spreads to the peritoneal cavity, and pathologic examination of peritoneal implants shows multiple nodules of mature thyroid tissue in varying sizes similar to struma ovarii (5). The differential diagnosis of peritoneal nodules of struma origin (termed struma peritonei) includes highly differentiated follicular

\footnotetext{
Received Sep. 29, 2014; revision accepted Oct. 27, 2014.

For correspondence or reprints contact: Sandip Basu, Radiation Medicine Centre, Bhabha Atomic Research Centre, Tata Memorial Hospital Annexe, Jerbai Wadia Rd., Parel, Mumbai, Maharashtra, India, 400012.

E-mail: drsanb@yahoo.com

Published online Dec. 23, 2014.

COPYRIGHT (C) 2015 by the Society of Nuclear Medicine and Molecular Imaging, Inc.
}

carcinoma of ovarian origin (HDFCO) (6) or typical thyroid carcinoma metastatic to the ovary (7). Because of its harmless and mature appearance histologically, HDFCO cannot be diagnosed until the neoplasm spreads beyond the ovary, showing evidence of aggressive behavior (6). Histologic features of thyroid carcinoma are found in 5\%-37\% of struma ovarii (referred to as malignant struma ovarii). The nuclear features of papillary carcinoma are usually used as the criteria for diagnosis of malignant struma ovarii, and most cases reported are papillary carcinoma $(5,8-10)$.

\section{CASE REPORT}

A 55-y-old woman with histopathologically confirmed struma ovarii, for which surgery had been undertaken $18 \mathrm{y}$ previously, presented with diarrhea and lower abdominal pain. She had a history of a similar presentation in a different center $6 \mathrm{y}$ after surgery, when a right iliac fossa mass $(7 \times 6 \mathrm{~cm})$ had been detected incidentally on ultrasonography. On CT of the abdomen, there was evidence of colonic and peritoneal nodules, and she had undergone revision surgery with removal of the right iliac fossa mass and colonic and peritoneal nodules. Histopathologic examination showed mature thyroid tissue containing many areas of follicular neoplasm, confirming it as struma peritonei. The iliac fossa mass was reported as recurrence of the struma ovarii.

On the present visit, abdominal ultrasonography showed multiple peritoneal deposits, solid echogenic space-occupying lesions in both lobes of the liver, a mixed echogenic mass with calcific foci within the pelvic region, and bilateral recurrence of adnexal masses. CT of the thorax showed multiple nodular lesions in both lungs highly suggestive of metastasis. Biopsy of the peritoneal nodules showed deposits of mature thyroid tissue containing many areas of follicular neoplasm, indicative of recurrence of struma peritonei. ${ }^{18} \mathrm{~F}-\mathrm{FDG}$ PET/CT showed multiple areas of lowgrade ${ }^{18} \mathrm{~F}-\mathrm{FDG}$ uptake in the liver and spleen and bilaterally in the lungs, as well as bilateral adnexal masses (Fig. 1) The neck was normal on ultrasonography. The patient underwent total thyroidectomy, with histopathologic examination indicating a normal thyroid gland and no evidence of malignancy. ${ }^{131} \mathrm{I}$ scanning (111 MBq [3 mCi]) $4 \mathrm{wk}$ 
FIGURE 1. ${ }^{18} \mathrm{~F}-\mathrm{FDG}$ PET/CT scan showing low-grade ${ }^{18} \mathrm{~F}-\mathrm{FDG}$ uptake (arrows) bilaterally in lungs (A), in spleen (B) and liver (C and $D)$, and bilaterally in uterine adnexa (E).

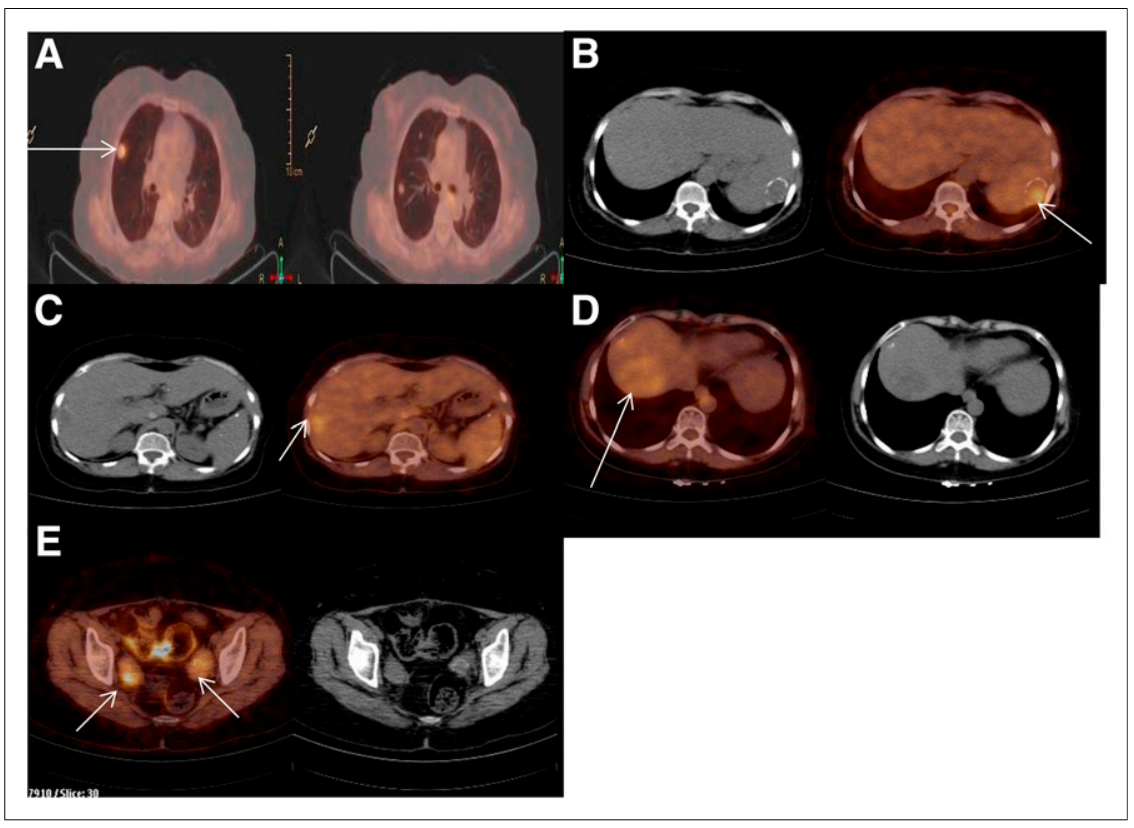

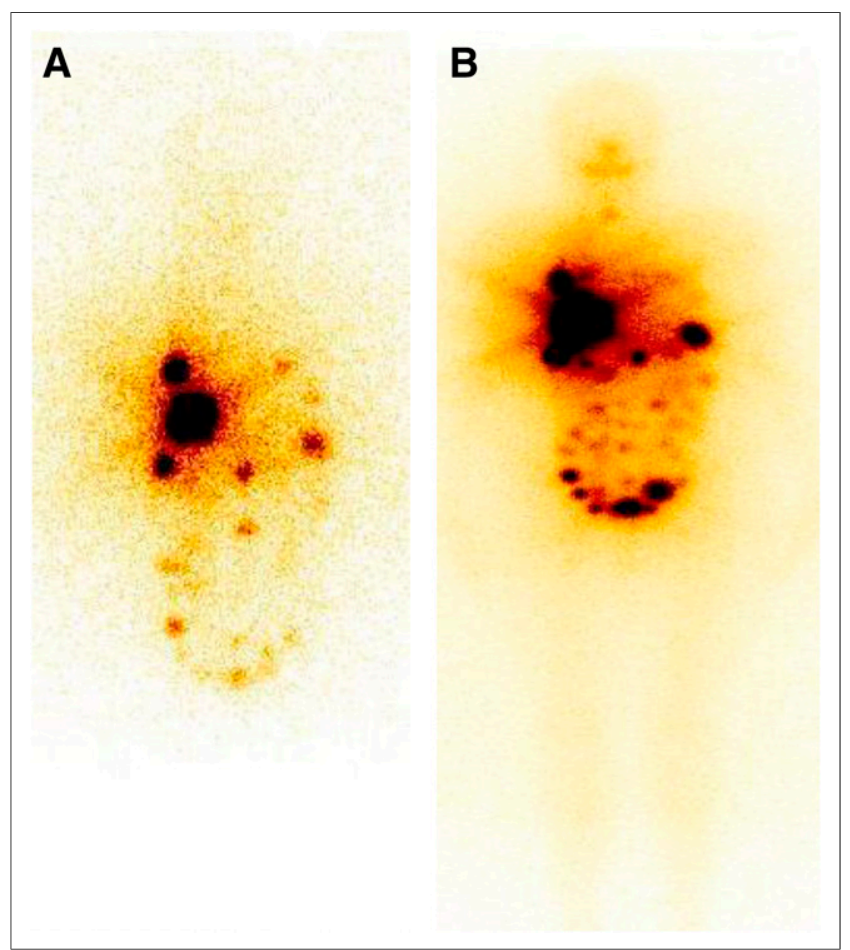

FIGURE 2. (A) Postsurgical diagnostic ${ }^{131}$ I scan demonstrating multiple iodine-avid lesions in liver, bilaterally in lungs, and in spleen. Also seen are multiple peritoneal deposits and bilateral pelvic deposits. (B) Posttherapy ${ }^{131}$ I scan showing more numerous peritoneal lesions than on diagnostic scan.

after surgery demonstrated multiple iodine-avid lesions in the liver, bilaterally in the lungs, and in the spleen, as well as multiple peritoneal deposits and bilateral pelvic deposits (Fig. 2A). After treatment with $7.4 \mathrm{GBq}$, a posttherapy ${ }^{131} \mathrm{I}$ scan (Fig. 2B) obtained at the time of discharge showed more numerous peritoneal lesions than on the diagnostic scan. At 3 mo after treatment, the patient was clinically euthyroid, with her thyroid profile (even without thyroxine suppression) showing a T4 level of $12.8 \mathrm{mg} / \mathrm{dL}$, an FT4 level of $1.88 \mathrm{ng} / \mathrm{dL}$, and a thyroid-stimulating hormone level of $0.0003 \mu \mathrm{IU} / \mathrm{mL}$ (demonstrating the highly functional nature of the metastatic lesions). The thyroid-stimulating hormone profile of the patient was being monitored every $6 \mathrm{wk}$. The serum thyroglobulin level was greater than $300 \mathrm{ng} / \mathrm{mL}$. At the time of writing, the patient is doing well on follow-up and is ambulatory. She is due for her next cycle of radioiodine therapy in $3 \mathrm{mo}$.

\section{DISCUSSION}

The literature on the course of malignant struma ovarii is based on case reports and series, the predominant sites of metastases being adjacent pelvic structures and peritoneum (11), but rarely also lungs, liver, brain, and skeleton. Roth et al. (6) evaluated the relationship of HDFCO and cases reported as struma peritonei and finally doubted the existence of the latter as a distinct clinicopathologic entity. They recommended an approach similar to the present strategy: local resection of the extraovarian tumor and subsequent thyroidectomy followed by radioactive iodine ablation.

Radioiodine scanning is considered the pivotal imaging modality in differentiated thyroid cancer, useful for detecting the presence of disease and for deciding on therapy. As seen in this case, struma peritonei consists mainly of differentiated thyroid tissue; radioiodine scanning should be integrated in the follow-up of such cases. ${ }^{123}$ I scanning is the preferred choice because of its superior imaging characteristics compared with ${ }^{131} \mathrm{I}$; however, the former is not yet available in all countries. The low 
${ }^{18} \mathrm{~F}-\mathrm{FDG}$ avidity of lesions on PET/CT is explained by the presence of differentiated thyroid tissue in the lesions and is in accord with its potential role in predicting disease biology.

\section{CONCLUSION}

The present case closely simulated HDFCO (6). There were 2 recurrences (at the sixth and 18th years after excision of struma ovarii, which was reported to be histopathologically benign), with only peritoneal metastasis being found during the first presentation but peritoneal and systemic dissemination being found during the second presentation. The functional nature (evidenced by a low thyroid-stimulating hormone level even without thyroxine suppression) and low to minimal ${ }^{18}$ F-FDG avidity of the foci are also noteworthy, because they reiterate the welldifferentiated nature of these lesions, as would theoretically be expected in HDFCO.

\section{DISCLOSURE}

No potential conflict of interest relevant to this article was reported.

\section{REFERENCES}

1. Serov SF, Scully RE, Sobin LH. International Histological Classification of Tumours, No. 9: Histological Typing of Ovarian Tumours. Geneva, Switzerland: World Health Organization; 1973.

2. Kabukcuoglu F, Baksu A, Yilmaz B, et al. Malignant struma ovarii. Pathol Oncol Res. 2002;8:145-147.

3. Rosenblum NG, LiVolsi VA, Edmonds PR, Mikuta JJ. Malignant struma ovarii. Gynecol Oncol. 1989;32:224-227.

4. Huh JJ, Montz FJ, Bristow RE. Struma ovarii associated with pseudo-Meigs' syndrome and elevated serum CA 125. Gynecol Oncol. 2002;86:231-234.

5. Devaney K, Snyder R, Norris HJ, Tavassoli FA. Proliferative and histologically malignant struma ovarii: a clinicopathologic study of 54 cases. Int J Gynecol Pathol. 1993;12:333-343.

6. Roth LM, Karseladze AI. Highly differentiated follicular carcinoma arising from struma ovarii: a report of 3 cases, a review of the literature, and a reassessment of so-called peritoneal strumosis. Int J Gynecol Pathol. 2008;27:213-222.

7. Brogioni S, Viacava P, Tomisti L, Martino E, Macchia E. A special case of bilateral ovarian metastases in a woman with papillary carcinoma of the thyroid. Exp Clin Endocrinol Diabetes. 2007;115:397-400.

8. Leite I, Cunha TM, Figueiredo JP, Félix A. Papillary carcinoma arising in struma ovarii versus ovarian metastasis from primary thyroid carcinoma: a case report and review of the literature. J Radiol Case Rep. 2013;7:24-33.

9. Medeiros F, Crum CP. Germ cell tumors of the ovary. In: Crum CP and Lee KR, eds. Diagnostic Gynecologic and Obstetric Pathology. Philadelphia, PA: Elsevier Saunders; 2006:920-921.

10. Robboy SJ, Pahisa J, Marquez M, Donohue J, Scully RE. Prognostic indices in malignant struma ovarii: a clinicopathological analysis of 36 patients with 20-year follow up [abstract]. Mod Pathol. 1995;8:95A.

11. Yassa L, Sadow P, Marqusee E. Malignant struma ovarii. Nat Clin Pract Endocrinol Metab. 2008;4:469-472. 